
\title{
$\begin{array}{ll}\text { Research Square } & \begin{array}{l}\text { Preprints are preliminary reports that have not undergone peer review. } \\ \text { They should not be considered conclusive, used to inform clinical practice, } \\ \text { or referenced by the media as validated information. }\end{array}\end{array}$ \\ Optimization of the separation paraments in inclined channels of liquid-solid fluidized bed
}

\section{yanfeng zhao}

School of Chemical Engineering and technology, China University of Mlning and Technology, Xuzhou, Jiangsu, 22116, China https://orcid.org/0000-0003-2879-6875

\section{Yanfeng Li ( $D$ lyf3344@126.com )}

Key Laboratory of Coal Processing and Efficient Utilization of Ministry of Education

\section{Peng Chen}

School of Chemical Engineering and Technology, China University of Mining and Technology,Xuzhou, Jiangsu, 22116, China

\section{Mengqi Ma}

School of Chemical Engineering and Technology, China University of MIning and Tecahnology, Xuzhou, Jiangsu, 221116, China

\section{Research}

Keywords: critical condition, channel space, solids throughput, split fluidization rate

Posted Date: July 8th, 2021

DOl: https://doi.org/10.21203/rs.3.rs-678817/v1

License: (c) (i) This work is licensed under a Creative Commons Attribution 4.0 International License.

Read Full License 


\title{
Optimization of the separation paraments in inclined channels of liquid-solid fluidized bed
}

\author{
Yanfeng Zhao ${ }^{a}$, Yanfeng $\mathrm{Li}^{a}{ }^{*}$, Peng Chen ${ }^{a}$, Mengqi Ma ${ }^{a}$

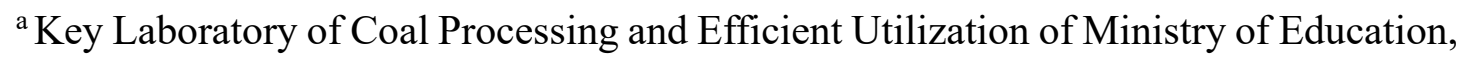 \\ School of Chemical Engineering and Technology, China University of Mining and \\ Technology, Xuzhou, Jiangsu, 221116, China. \\ *Address correspondence to Yanfeng Li, E-mail:lyf3344@126.com
}

\begin{abstract}
A new theoretical formula can be used to calculate superficial velocity for particle separation with a critical condition, and it is based on the size, density, terminal velocity, Reynold number of the particle and equipment parameters. In a continuous system, a series of fractionation experiments were conducted to quantify the separation performance for 0-2 $\mathrm{mm}$ coal particles under various factors, including channel spacing, solids throughput and split fluidization rate. The separation performance considers the ash content and yield of products varying with the particle size. A great fluidization environment can be created by the $6 \mathrm{~mm}$ channel spacing. For the solids throughput of $10.20 \mathrm{t} /\left(\mathrm{m}^{2} \mathrm{~h}\right)$ provides a well effective separation in the narrow channels. In addition, the split fluidization of $0.0058 \mathrm{~m} / \mathrm{s}$ can produce a higher shear induce force in the inclined channels to prevent the low-density particles from being lost in the underflow. The theoretical superficial velocity calculated by the new formula is $0.042 \mathrm{~m} / \mathrm{s}$, which can report the particles with the upper and lower size reach at 9-fold to the overflow, it is almost the same as the actual separation fluidization velocity of $0.04 \mathrm{~m} / \mathrm{s}$. Meanwhile, the data obtained under each separation condition is basically consistent with data of the sink-float mothed, which shows a good separation performance for the Reflux Classifier.
\end{abstract}

Keywords: critical condition; channel space; solids throughput; split fluidization rate;

\section{Introduction}

With the development of gravity concentration technology in the mineral industry, the gravity separation devices are commonly applied for collecting the valuable products in the mineral processing [1]. The fluidized bed is a classical gravity hydraulic separation equipment, which can be obtained a better result by changing the superficial fluid velocity or discharging the rate via the bottom [2,3]. Ideally, a perfect separation was produced in the gravity equipment basing on the particle density and greatly 
suppressing the effort of size and shape of particle [4,5]. However, in practice, with a wide range of feed size, the separation performance is obviously affected by size which getting a deterioration of elutriation and the ash content of the clean products to higher. Therefore, it is a big challenge for an alternative technique to suppress the impact of size in the process [4].

A relatively new gravity separation equipment, Reflux classifier (RC), was combined a set of parallel inclined channels with a conventional fluidized bed, as shown in Fig. 1 [6,7,8], and it has been studied for decade years. The Boycott effect was discovered, which made a significant benefit for the high hydraulic loading due to a large effective settlement area in the inclined channels $[9,10]$. Meanwhile, in the inclined channels, the laminar-shear mechanism causes the low-density coarse particles are easily tending to be re-suspended, which largely enhanced the efficiency of RC basis of density separation [11,12,13]. Follow, an empirical formula was introduced to quantify the separation efficiency by Laskowski et al, and it was according to the kinematic theory proposed by Ponder and Nakamura and Kuroda (PNK theory) $[14,15]$. However, in the further research, the final elutriation separation size initial decrease followed by a gradually increase as the number of inclined channels raise [12]. However, those previous key theories only offer a computational method of separation in the wide inclined channels.

Recently, with the development of RC, a new mechanism described by Galvin who had found an elutriation basically based on particle density in the narrow spacing channels [5]. As the Fig. 2 shows, in the laminar flow, a parabolic velocity profile was developed within the channel, the particles on the surface of plate whose local fluid velocity are linear with their half of the diameter, which shown that the coarse particles accompanying the higher local fluid velocity, while the fine particles are opposite [5]. If the local fluid velocity of the particles is equal to the sedimentation velocity of the particles along the tangential plate surface, the particles will reach an equilibrium position in the tangential direction. In a narrow channel, different locations in the channel have different local fluid velocities, this will subject the particles to lifting forces. The introduction of inertial lifting force standard can determine the possibility of particles entering high fluid velocity from the surface of the plate or staying on the wall at low fluid velocity [17]. In the comprehensive fluid, the particles whose lift force exceeds the net weight force in the normal direction, they can be conveyed up along the 
upper plate, conversely, those particles will be slipped down along the lower plate surface to the fluid region under the inclined channels. Therefore, He provided a model of particles movement based on those conditions of the lift force equal to net weight force in the normal direction and the superficial fluid velocity match to the terminal velocity in the tangential direction, however, there is an intermediate variable in that paper [18]. For the sake of simplicity, this paper provides a new equation to calculate the critical superficial fluid velocity.

This paper is concerned with the new formula to describe the critical superficial fluid velocity in the continuous process. Previous works about coal or mineral corresponding to the narrow channels gap under the laminar flow have been proved to be satisfactory $[21,22,23]$. Some single factor experiments were conducted to explore the potentiality ranges of various operational parameters in the continuous segregation. Those factors are included of channels spacing, solid throughput and split fluidization rate. The products of overflow and underflow elutriated at each condition were sized, weighed and analyzed, meanwhile, quantified the separation performance both in the size-ash curves and washability curve. The results of each operating parameter are provided a couple of guidance laboratory-scale experimental for the actual process of $\mathrm{RC}$ in coal and mineral processing field.

\section{Experimental theory}

The particle movement is determined by the particle density, size and flow characteristics during the particle settling. The forces of the particles received in the fluid are very complicated, so a coordinate system was established. It can be decomposed into the tangential component and normal component, in which y denotes the tangential direction, and $\mathrm{x}$ the normal direction, as shown in Fig.2. The flow rate of the center of the channel and near the plate surface are not consistent. The flow rate in the center of channel is 1.5 times of the superficial velocity, while the flow rate near the plate surface is less than the superficial velocity. So, a high fluidization gradient was developed in the inclined channels. The pressure on the upper and lower surfaces of the particle are different because of a high fluid velocity gradient, which result in a high inertial lift experienced at particle.

$$
\mathrm{J}=\frac{R_{e s}^{2}}{R_{e x}}
$$


Where $R_{e s}$ is the shear Reynolds number, $R_{e x}$ is the particle Reynolds number in the normal direction. If $\mathrm{J}$ is greater than 32 , the particle will be migrated toward the highfluid velocity region under the shear lift force. If $\mathrm{J}$ is less than 32 , the result is just be converse. Meanwhile, the $R_{e x}$ is expressed as :

$$
R_{e x}=R_{e t} \cos \theta
$$

where $R_{e t}$ is the particle Reynolds number in the flow, $\theta$ is the inclination angle relative to the horizontal. Zigzag and Sylvester provided a theoretical description of the particle Reynolds number suspended in the liquid, therefor, the $U_{t}$ can be conveniently obtained from the particle Reynolds number

$$
\begin{aligned}
& R_{e t}=\left[\left(14.51+\left(g *\left(\rho_{p}-\rho_{f}\right) * \rho_{f}\right)^{0.5} * 1.83 * \frac{d^{1.5}}{\mu}\right)^{0.5}-3.81\right]^{2} \\
& U_{T Y}=U_{t} \sin \theta \\
& R_{e t}=\frac{\rho_{f} U_{T} d}{\mu}
\end{aligned}
$$

Where $\mathrm{g}$ is acceleration of gravity, the $U_{T Y}$ is particle terminal velocity in the $\mathrm{Y}$ direction, $U_{T}$ is the particle terminal velocity, $\mathrm{d}$ is particle diameter, $\rho_{f}$ is the density of the fluid, $g$ is the gravitational acceleration, $\mu$ is the fluid viscosity. The shear Reynolds number, $R_{e s}$, it is conveniently obtained by :

$$
R_{e s}=\frac{\rho_{f} \gamma d^{2}}{\mu}
$$

Where $\gamma$ is the velocity gradient, and $\mathrm{z}$ is spaced of channels, the velocity gradient can be calculated by differentiating Eq.(8), which was shown that:

$$
\begin{aligned}
& \gamma=\frac{6 U}{z}\left(1-\frac{2 x}{z}\right) \\
& u_{(x)}=\frac{6 U x}{z}\left(1-\frac{x}{z}\right)
\end{aligned}
$$

where $U$ is the average superficial velocity, and $x$ is the distance of particle from the wall, and $u_{(x)}$ is the local fluid velocity. When the $J$ is less than 32 , the sum of the lifting force and buoyancy of the particle is less than gravity force, which lead particles drop down and settle on the plate surface. When settling velocity of particles in the 
tangential direction is equal to the fluidization velocity at the particle center, so, it means that an equilibrium state will be reached in this condition for those particles.

$$
U_{T Y}=U_{d / 2}
$$

As $\mathrm{x}=\frac{d}{2}$, by combining the $\mathrm{Eq}(3), \mathrm{Eq}(8)$ and $\mathrm{Eq}(9)$ the superficial velocity of inclined channel can be calculated :

$$
\mathrm{U}=\frac{z U_{T} z^{2} \sin \theta}{3 d(2 z-d)}
$$

When the $\mathrm{J}$ greater than 32 , the particles will be suspended at a distance $\mathrm{x}$ from the surface of the plate and reached a critical balanced position. Substituting Eq (1), Eq (2), $\mathrm{Eq}(3), \mathrm{Eq}(4), \mathrm{Eq}$ (5), Eq (6), Eq (7) lead to define the critical hydraulic velocity. That is,

$$
\begin{aligned}
& \mathrm{U}=\frac{\sqrt{8} z^{2} \mu R_{e x}^{o .5}}{3 \rho d^{2}(z-2 x)} \\
& \mathrm{U}=\frac{z U_{t} \sin \theta}{6 x\left(1-\frac{x}{z}\right)}
\end{aligned}
$$

However, there is $\mathrm{x}$ both in these two formulas of express critical superficial velocity, so, it is not conveniently to calculate the critical superficial velocity for the given feed particles. Therefore, a new formula free of $\mathrm{x}$ can be concluded by combining the two formulas above. So, combining the $\mathrm{Eq}(9)$ with $\mathrm{Eq}(10)$ the formula can be introduced as:

$$
\mathrm{U}=\frac{U_{T} \sin \theta-\left(U_{T}^{2} \sin \theta^{2}+\frac{8 z^{2} \mu^{2} R e x}{\rho^{2} d^{4}}\right)^{0.5}}{3}
$$

Eq. (13), it is described the quantitative relationship based on the superficial velocity, $\mathrm{U}$, of a fluid attend an inclined channel of gap, $\mathrm{z}$, the inclination angle relative to the horizontal $\theta$, the density of the particle, $\rho$, the gravitational acceleration, $g$, the fluid viscosity, $\mu$ and the particle diameter $\mathrm{d}$.

It is evident that the index of particle size effect in this new formula is reduced to 0.5 power dependency. So, the dependence on particle size in the inclined channel is 
largely reduced and promoted the separation based on the particle density. In this paper, the value of critical superficial velocity is expressed in new formula to obtain a better quality for the given feed, which is significant directions for our laboratory-scale separation.

\section{Experiments}

To investigate the influence of channel spacing, solids throughput and split fluidization rate on the separation result, a continuous experiment system is established. The system is consisted of the incline zone and vertical zone. The inclined section contains some isometric inclined channels is constructed from Perspex, it is at an angle of $70^{\circ}$ to the horizontal, connecting with a horizontal cross-sectional $60 \mathrm{~mm}$ wide by $100 \mathrm{~mm}$ broad and a height of $800 \mathrm{~mm}$. With $0.6 \mathrm{~mm}$ thick inclined plates are inserted and slightly higher than the overflow weir, so that to create a common parallel flow environment in each channel. The vertical zone is connected to bottom of the incline zone, having a cross sectional area of $60 \mathrm{~mm} \times 100 \mathrm{~mm}$ and height of $800 \mathrm{~mm}$. There is a distributor at the base of the vertical section, it can be allowed the fluidization water uniformly added in the system, which can ensure the suspension keep a fluidization within the equipment.

The particle properties are presented in detail, as shown in Tab 1. and Tab 2. It can be easily found that with the particle size decreasing from the $2 \mathrm{~mm}$ to $0.125 \mathrm{~mm}$, the ash content feed is increases at first and then decreases. And the feed density is mainly concentrated in $1250-1400 \mathrm{~kg} / \mathrm{m}^{3}$, and the material yield of each density level is basically uniform. Therefore, the material cannot get a better product by classification, and can only get a better separation result by gravity separation. Before adding the suspension into the system, it should be switched on the fluidization water valve and maintained a minimum fluidization velocity to ensure the suspension was dispersion. Once the fluidization water flows into the overflow weir, the feed pump and the underflow pump should be immediately switched on. With an increasing feed particle added into the vertical region, a dense autogenous bed was gradually formed. After a while, some tests were taken to verify whether the system has reached a stable state. Under the stable state, the system was kept at a fixed fluidization velocity lasted over $1 \mathrm{~h}$, before the next operating conditions change made. The coarse particles were easily to settle on the plate surface, so they basically slide down to the bottom of the vertical section, while the fine particles with a slowly setting velocity are conveyed up the 
inclined channels and flowed into the overflow weir to be collected. Meanwhile, the overflow solids passing through the $0.075 \mathrm{~mm}$ filter screen is collected. Then, analyzing the overflow and underflow products recovered from each steady-state condition to characterize the separation performance to bring some suggestion to future experiments.

\section{Results and discussion}

\subsection{Effect of channel spacing on separation}

The different hydraulic gradients are developed within various channel spacings, the particle moves from the boundary of the channel to the center of the channel, its superficial velocity increases from 0 to 1.5 times of the average flow rate of channels. In the new formula, it is shown that a wider channel requires a higher fluidization velocity to obtain an equilibrium state for a given feed. In other words, for a fixed fluidization rate, the narrower the channel, the larger the particle size is needed to reach the critical balance. The value of superficial velocity is equal to the value of average flowrate in the inclined channel, and the particles are experienced a lower lift force than the narrow channels in wide channel. Therefore, it can be inferred that the ash content of the underflow in the wide channel is lower than that of narrow inclined channel, as result of a few low-density particles losing in underflow under the same superficial velocity. Aim to confirm this hypothesis, runs 1, 2 and 3 were conducted. Tab. 3 provides a summary of the operating conditions used in the experiment.

Fig. 5a shows the ash of overflow as a function of the channel spacing and particle size, respectively. The ash content of products generated from $6 \mathrm{~mm}$ spacing is slightly lower than that of $14 \mathrm{~mm}$ channel spacing in the whole particle size range, and there is a little fluctuation at the size range of $0.75-2 \mathrm{~mm}$ in the $14 \mathrm{~mm}$ channels spacing. In addition, the $22 \mathrm{~mm}$ channel spacing is the highest grade of ash for particles size less than $0.125 \mathrm{~mm}$. The main reason is that the high superficial velocity leads to high-ash fine particles to overflow in wide channel spacing. It is evidenced that the ash content of each product decreases with increasing particle size, it is tending to be a fixed ash value of $2.50 \%$. So, it shows that the inclined channel can obviously strengthen the density separation. When the particle size is less than $0.1 \mathrm{~mm}$, the spacing of $22 \mathrm{~mm}$ shows a better agreement with the feed ash-size curve. And for the size greater than 0.1 $\mathrm{mm}$, the ash content decreases with an increase in particle size, and its trend is common in the traditional hydraulic gravity separation equipment. It can be concluded that the 
particle size has a higher significantly effect on the separation of wide channel.

Fig. 5b shows the ash content of underflow as a function of the channel spacings and size, respectively. The underflow ash \% of the of $22 \mathrm{~mm}$ spacing is lower than that of $6 \mathrm{~mm}$ and $14 \mathrm{~mm}$ for particle size below $1 \mathrm{~mm}$, which strongly demonstrates that some low-density particles are lost in the wide channel underflow. Moreover, the separation data of channel spacing of $14 \mathrm{~mm}$ and $22 \mathrm{~mm}$ for the particle size range of $1-2 \mathrm{~mm}$ shows an almost same result of ash \%, and the data of the $6 \mathrm{~mm}$ spacing is higher than that of channel spacing of $14 \mathrm{~mm}$ and $22 \mathrm{~mm}$ for a given size. With a high lift force of the narrow channel, the re-suspension is more obvious, which makes it easier for coarse particles to be conveyed to the overflow making the underflow ash content of the narrow channel higher. By comparing the difference between the overflow ash content and the underflow content at each particle size in the three experiments, it is evidenced that the over-size spacing will increase the difficulty to produce high-grade products.

\subsection{Effort of solids throughput on the separation.}

Throughput is one of the main parameters of the gravity separation equipmentes, and the processing capability of the equipment rapidly decreases as the feed particle size decrease. Over $17 \mathrm{t} /\left(\mathrm{m}^{2} \mathrm{~h}\right)$ solids throughput for the traditional liquid-solid fluidized bed processes the particle size ranging from $0.25 \mathrm{~mm}$ to $1 \mathrm{~mm}$. To investigate the solids throughput potential in the inclined channel, the solids throughput of $5 \mathrm{t} /$ $\left(\mathrm{m}^{2} \mathrm{~h}\right), 10.20 \mathrm{t} /\left(\mathrm{m}^{2} \mathrm{~h}\right)$ and $18.33 \mathrm{t} /\left(\mathrm{m}^{2} \mathrm{~h}\right)$ were used in this work. It is worth noted that the value of the maximum throughput can only be reached at $18.33 \mathrm{t} /\left(\mathrm{m}^{2} \mathrm{~h}\right)$ as the limitation of the equipment and system.

Fig. 6a shows the separation results of overflow using various throughput values for the $6 \mathrm{~mm}$ channel spacing. For the particle size greater than $0.125 \mathrm{~mm}$, the ash value obtained by $10.20 \mathrm{t} /\left(\mathrm{m}^{2} \mathrm{~h}\right)$ and $5.00 \mathrm{t} /\left(\mathrm{m}^{2} \mathrm{~h}\right)$ separations decreased with the increase of particle size, and the difference of ash value between them was small. Meanwhile, with a throughput of $18.33 \mathrm{t} /\left(\mathrm{m}^{2} \mathrm{~h}\right)$ provide the highest ash \% within this size range. In the particle size range of $-0.125 \mathrm{~mm}$, the ash value of three different experiments increases rapidly with the decrease of the particle size, and the ash value between them is very diversity. Since the relatively high throughput leads to an increase in superficial velocity, with a result that the high ash content fines whose size below the $0.125 \mathrm{~mm}$ are conveyed up to the overflow. 
Fig. 6b shows the separation results of underflow using various throughput values with the $6 \mathrm{~mm}$ channel spaced. The throughput of $10.20 \mathrm{t} /\left(\mathrm{m}^{2} \mathrm{~h}\right)$ curve shows a good agreement with that of $18.33 \mathrm{t} /\left(\mathrm{m}^{2} \mathrm{~h}\right)$ curve for the particle size larger than $0.75 \mathrm{~mm}$, and within the same particle size range, the ash content of produced $\%$ by the 5.00 $\mathrm{t} /\left(\mathrm{m}^{2} \mathrm{~h}\right)$ is lower than that of the $10.20 \mathrm{t} /\left(\mathrm{m}^{2} \mathrm{~h}\right)$ and $18.33 \mathrm{t} /\left(\mathrm{m}^{2} \mathrm{~h}\right)$. However, as the particle size is less than $0.75 \mathrm{~mm}$ and gradually decreases, curve of $10.20 \mathrm{t} /\left(\mathrm{m}^{2} \mathrm{~h}\right)$ and curve of $18.33 \mathrm{t} /\left(\mathrm{m}^{2} \mathrm{~h}\right)$ tend to overlap, indicating that their separation performance is very similar. It should be noted that for most particle sizes, the data obtained from the separation of $10.20 \mathrm{t} /\left(\mathrm{m}^{2} \mathrm{~h}\right)$ is higher than that of $18.33 \mathrm{t} /\left(\mathrm{m}^{2} \mathrm{~h}\right)$ and $5.00 \mathrm{t} /\left(\mathrm{m}^{2} \mathrm{~h}\right)$. As a result, the throughput of $10.20 \mathrm{t} /\left(\mathrm{m}^{2} \mathrm{~h}\right)$ can bring a moderate separation environment.

\subsection{The influence of split fluidization rate on separation}

The theory of split fluidization is based on the separation principles of the inclined channel and liquid-solid fluidized bed. The fluidized water is introduced into the system, which includes split water added from the position below the feed pipe and fluidized water directly added to the distributor at the base of the RC. Goals of split fluidization are to resolve the low-density particles easily lost into underflow and to provide a moderate separation environment for the inclined channel and fluidized bed. Two comparative experiments (Run 1 and Run 6) were conducted in this section, both of their feed volumetric rate puts into the vertical section is $3.68 \mathrm{~kg} / \mathrm{min}$ that equals to $0.0102 \mathrm{~m} / \mathrm{s}$. The Run 1 does not add split fluidization water, but the rate of $2.08 \mathrm{~kg} / \mathrm{min}$ fluidization water is added to the Run 6 experiment.

Fig. 7a shows that the ash value of the overflow relates with the split fluidization in the separation. After introducing the split fluidization water into system, the ash content is slightly reduced within the particle size range of $0.25-1.45 \mathrm{~mm}$, meanwhile, it rapidly increases from $8.85 \%$ to $15.6 \%$ as the particle size is reduced to $0.25 \mathrm{~mm}$. The superficial fluidization velocity is increased with an increase in the split fluidization rate. However, the high superficial velocity, which maybe disrupt the stable laminar flow, has a significant influence on the separation of fines. In practice, most of fines have analogous terminal velocity in the infinite settling flow, which indicates that their movement in separation are slightly different.

Fig. $7 \mathbf{b}$ shows that the ash value of the underflow relates with the split fluidization in the separation. When accompanying the split fluidization water is put into the vertical section, the content of ash presents a decrease from $80.12 \%$ to $17.79 \%$ at the particle 
size range of $0.125-1.0 \mathrm{~mm}$ since a few lower density particles mixed with the underflow stream. Moreover, the ash content of underflow exhibits a not obviously decrease as the particle size range from $1 \mathrm{~mm}$ to $2 \mathrm{~mm}$. It is evident that the split fluidization can prevent the coarse particles of low-density from mixing into the underflow, but inevitably increase the ash content of the overflow. Therefore, the way of the split fluidization has a limited improvement of separation performance in the inclined channel process.

\subsection{Separation effect of slime in the inclined close channels}

The liquid -solid fluidization bed has a best separation efficiency when the particle size of feed is within the range of $0.25 \mathrm{~mm}$ to $1 \mathrm{~mm}$, which is commonly applied to the elutriation of coal slime. When the difficult washability feed particles with wide range size are entered the liquid-solid separation bed, a poor separation performance will be showed in the process. This specific performance is an amount of the high ash content fine gangue particles transported to the underflow making a low-grade clean coal through overflow, and further stages are inevitably added to elutriate slime. Meanwhile, a few coarse particles of low-density are misplaced in the underflow and the tailings have low ash content and recovery rate, and these separation features are commonly found in the liquid -solid separation and other hydraulic separators since the separation performances are affect by the particle size. From the view of Ep, the value of Ep increases with the decreasing feed particle size, and from the separation density of each size product, the separation density of coarse particles is low while the fine is the opposite. As far as the product ash content of each size, it obviously varies with the particle size.

Fig. 8 shows that the particle size relation with ash content of overflow for Run 1, 5,6 . The ash content is almost kept at around $3.65 \%$ for the overflow products coving the size range $0.2-1.8 \mathrm{~mm}$, in other words, the ash content slightly fluctuates with the change of the particle size, and it means that the separation density is similar, and the value of Ep is low. So, the inclined channel provides a better separation performance under the gravity force. The ratio of upper and lower feed particle size is 9 times in the inclined channels, which is different from 4 times of the liquid -solid separation bed. It is evident that the separation performance of the inclined channels is better than that of the liquid -solid separation bed for the feed particle with wide size range.

According to the density of each particle size of the overflow products, the 
relationship between the particle size predicted by the new model and the corresponding superficial velocity is plotted in Fig. 8. For the $U=0.042 \mathrm{~m} / \mathrm{s}$, the particles of covering the size range $0.2-1.8 \mathrm{~mm}$ are conveyed to the overflow with almost similarly probability, this separation is nearly dependent on the particle density. The predict of superficial velocity shows a good agreement with the experiment result. In the continuous system, it should be noted that the predict fluidization velocity is $0.042 \mathrm{~m} / \mathrm{s}$, while the experimental value is $0.04 \mathrm{~m} / \mathrm{s}$, and the reason for the difference is the effect of hindered settling within suspension particles. However, since the predicted fluidization velocity is of the same order of magnitude as the experimental fluidization velocity, it will not affect the application of critical models in inclined channels significantly.

Fig. 9 shows the cumulative yield versus cumulative ash \% curve in the continuous separation. High shear flow environment in the narrow channels enhances the separation performance according to particle density. The overflow curve generated by $6 \mathrm{~mm}$ spacing is closer to the sink-float curve than that of the spacing of $14 \mathrm{~mm}$ and 22 $\mathrm{mm}$, which is consistent with Fig. 1. As the channel spacing increases, the overflow will be deteriorated, the overflow ash content of the $22 \mathrm{~mm}$ channel is higher than that of the $6 \mathrm{~mm}$ and $14 \mathrm{~mm}$ channels. So, the $6 \mathrm{~mm}$ channel spacing provides a better separation performance. Compared with Run 1, the Runs 4,5 have higher solid throughput. The data generated by Run 1 and Run 5 are below the sink-float curve, while the data generated by Run 4 separation is closer to the sink-float curve, which shows a better separation performance, it can also be confirmed in Fig. 5. The Run 1 and Run 6 are operated under different fluidization conditions, and the data obtained by Run 6 is obviously closer to the float-sink curve at the given ash \% than that generated by Run1, and this result is consistent with Fig. 7. In general, the value of the overflow product under different separation conditions is very close to the value of the sink-float experiment indicating that the inclined channel can indeed improve the density separation.

\section{Conclusions}

In this paper, the experimental results show that a better separation performance can be obtained when the channel spacing is $6 \mathrm{~mm}$, and the corresponding overflow ash content is lower, and the underflow ash content is higher for the feed particle size of 0 $-2 \mathrm{~mm}$ in continuous separation. When the inclined channel spacing increases to $22 \mathrm{~mm}$, 
the increase in superficial velocity makes a certain low-density particle enter the underflow resulting in low ash content of the underflow. Meanwhile, there is a moderate separation environment when the value of throughput is obtained at $10.20 \mathrm{t} /\left(\mathrm{m}^{2} \mathrm{~h}\right)$. The mothed of the split fluidization can produce a better environment for the low-density particles reporting to the overflow, and it also increases the ash of underflow suppressing the size effort in the inclined channels. In general, addition to $0-0.125 \mathrm{~mm}$ particles in overflow products, when the average particle size of products increases from $0.2 \mathrm{~mm}$ to $1.73 \mathrm{~mm}$, the ash content basically remains at about $3.63 \%$. It indicates that the influence of particle size on separation performance has been improved. It can be seen from the experimental results that the particles with the size of $0.2-0.18 \mathrm{~mm}$ are transported to the overflow. When the velocity of flow in the inclined channel is 0.042 $\mathrm{m} / \mathrm{s}$, this result is consistent with the separation according to the particle density which further showing that the model is practical.

\section{Declaration}

We declare that we have no financial and personal relationships with other people or organizations that can inappropriately influence our work, there is no professional or other personal interest of any nature or kind in any product, service and/or company that could be construed as influencing the position presented in, or the review of, the manuscript entitled "Optimization of the separation paraments in inclined channels of liquid-solid fluidized bed".

\section{Acknowledgements}

This paper was supported by National Natural Science Foundation of China (Grant NO. 51674258) and the Priority Academic Program Development of Jiangsu Higher Education Institutions.

\section{References}

[1] Walton K, Zhou J, Galvin, KP (2010) Processing of fine particles using closely spaced inclined channels. Advanced Powder Technology 21(4):386-391. http://doi.org/10.1016/j.apt. 2010.02.015

[2] Galvin KP, Pratten SJ, Lambert N, Callen AM, Lui J (2002). Influence of a jigging a ction on the gravity separation achieved in a teetered bed separator. Minerals Engineering 15(12):1199-1202. http://doi.org/10.1016/S0892-6875(02)00211-X

[3] Epstein, N, Pruden BB (1998). Liquid fluidisation of binary particle mixtures-iii strati fication by size and related topics. Chemical Engineering Science 54(54):401-415. http://do 
i.org/10.1016/S0009-2509(98)00250-4

[4] Galvin KP, Zhou J, Walton K (2010). Application of closely spaced inclined channels in gravity separation of fine particles. Minerals Engineering 23(4):326-338. http://doi.org/10. 1016/j.mineng.2009.09.015

[5] Galvin KP, Walton K, Zhou J (2009). How to elutriate particles according to their den sity. Chemical Engineering Science 64(9):2003-2010. http://doi.org/2003-2010. 10.1016/j.ces. 2009.01 .031

[6] Galvin KP, Doroodchi E, Callenm AM, Lambert N, Pratten SJ (2002). Pilot plant trial of the reflux classifier. Minerals Engineering 15(1):19-25. http://doi.org/10.1016/S0892-6875 (01)00193-5

[7] Carpenter JL, Zhou J, Iveson SM, Galvin KP (2019). Gravity separation in the reflux classifier in the presence of slimes. Minerals Engineering 143(16):105941. http://doi.org/10. 1016/j.mineng.2019.105941

[8] Galvin, KP, Callen A, Zhou J, Doroodchi E (2005). Performance of the reflux classifie r for gravity separation at full scale. Minerals Engineering 18(1):19-24. http://doi.org/10.101 6/j.mineng.2004.05.023

[9] BOYCOTT, AE (1920). Sedimentation of blood corpuscles. Nature 104(2621):532-532. http://doi.org/10.1038/104532b0

[10] Hunter DM, Iveson SM, Galvin KP (2014). The role of viscosity in the density fracti onation of particles in a laboratory-scale reflux classifier. Fuel 129(aug.1):188-196. http://do i.org/10.1016/j.fuel.2014.03.063

[11] Galvin KP, Nguyentranlam G (2002). Influence of parallel inclined plates in a liquid fluidized bed system. Chemical Engineering Science 57(7):1231-1234. http://doi.org/10.1016/ S0009-2509(02)00005-2

[12] D Laskovski, Duncan P, Stevenson P, Zhou J, Galvin KP (2006). Segregation of hydr aulically suspended particles in inclined channels. Chemical Engineering Science 61(22):726 9-7278. htttp://doi.org/ 10.1016/j.ces.2006.08.024

[13] Galvin KP, Liu H (2011). Role of inertial lift in elutriating particles according to thei r density. Chemical Engineering Science 66(16):3687-3691. http://doi.org/10.1016/j.ces.2011. 05.002

[14] Pon DeR, E (1925). On sedimentation and rouleaux formation-i. Experimental Physiol ogy 15. http://doi.org/10.1113/expphysiol.1925.sp.000356

[15] Nakamura H, Kuroda K (1937). La cause de l'acceleration de la vitesse de sedimenta tion des suspensions dans les recipients inclines. Keijo J Med 8:256-296. 
[16] Zhou J, Walton K, Laskovski D, Duncan P, Galvin KP (2006). Enhanced separation of mineral sands using the reflux classifier. Minerals Engineering 19(15):1573-1579. http://d oi.org/10.1016/j.mineng.2006.08.009

[17] King MR, Leighton DT (1997). Measurement of the inertial lift on a moving sphere in contact with a plane wall in a shear flow. Physics of Fluids 9(5):1248-1255. http://doi.o rg/10.1063/1.869264

[18] He S, Y Li, Liu T, Chen P, Yin, M (2020). A novel model for critical motion of pa rticles in inclined channels of liquid-solid separation fluidized bed. Powder Technology 36 9. http://doi.org/10.1016/j.powtec.2020.05.028

[19] B Bird, WE Stewart, EN Lightfoot (1960). Transport phenomena Wiley, New York 7 80. http://doi.org/10.1002/aic.690070245

[20] Krishnan, GP, Leighton DT (1995). Inertial lift on a moving sphere in contact with a plane wall in a shear flow. Physics of Fluids 7(11):2538-2545. http://doi.org/10.1063/1.868 $\underline{755}$

[21] Nguyentranlam, G, \& Galvin, KP (2001). Particle classification in the reflux classifier. Minerals Engineering 14(9):1081-1091. http://doi.org/10.1016/S0892-6875(01)00113-3

[22] Galvin KP, Iveson SM, Zhou J, Lowes CP (2020). Influence of inclined channel spac ing on dense mineral partition in a reflux classifier. part 2: water based fractionation. Min erals Engineering 155, 106442. http://doi.org/10.1016/j.mineng.2020.106442

[23] Walton K, Zhou J, Galvin KP (2010). Processing of fine particles using closely space d inclined channels. Advanced Powder Technology 21(4): 386-391. http://doi.org/ 10.1016/j. apt.2010.02.015 
Figures
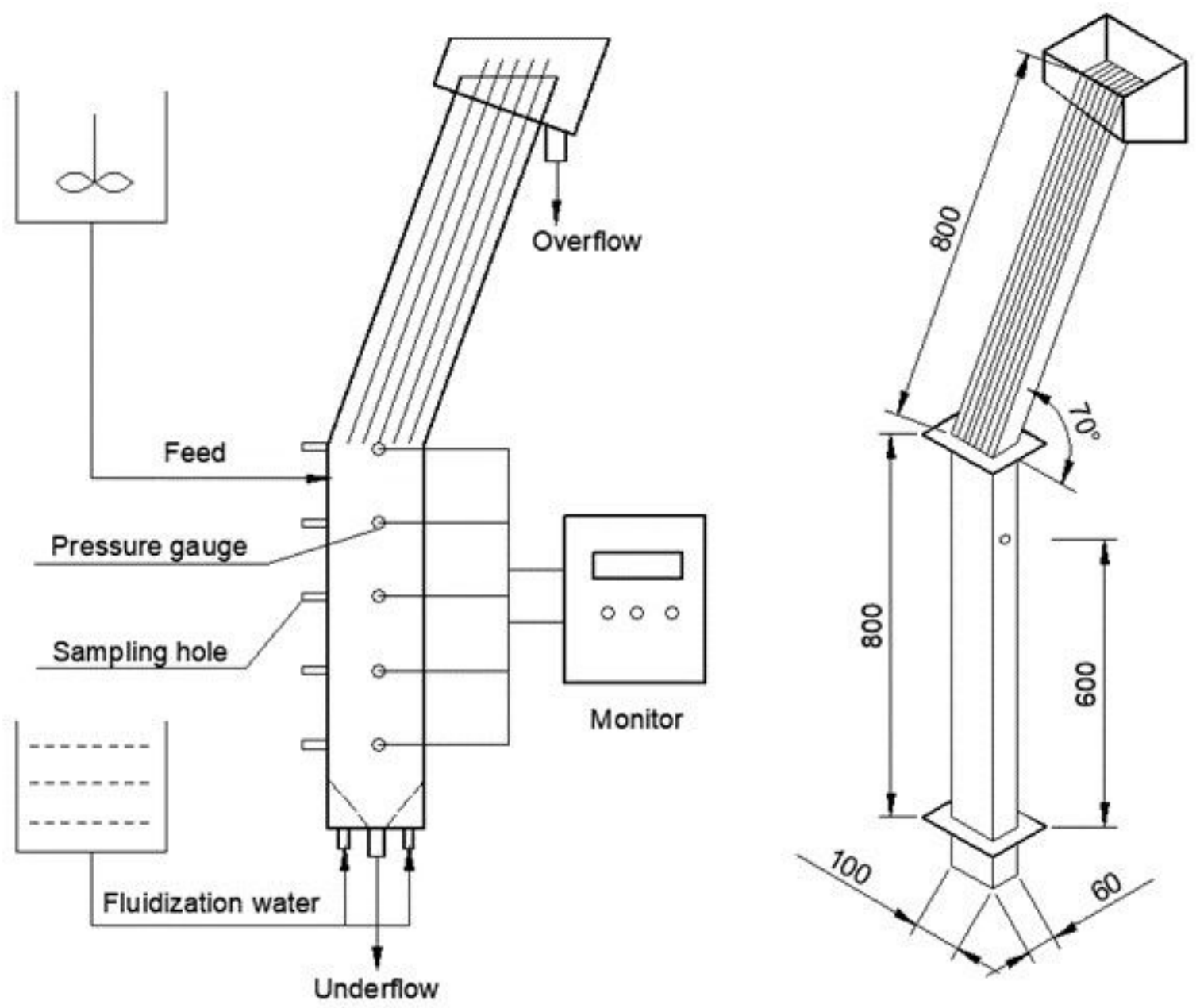

Figure 1

Figure 1 - Schematic of a Reflux Classifier [18] 


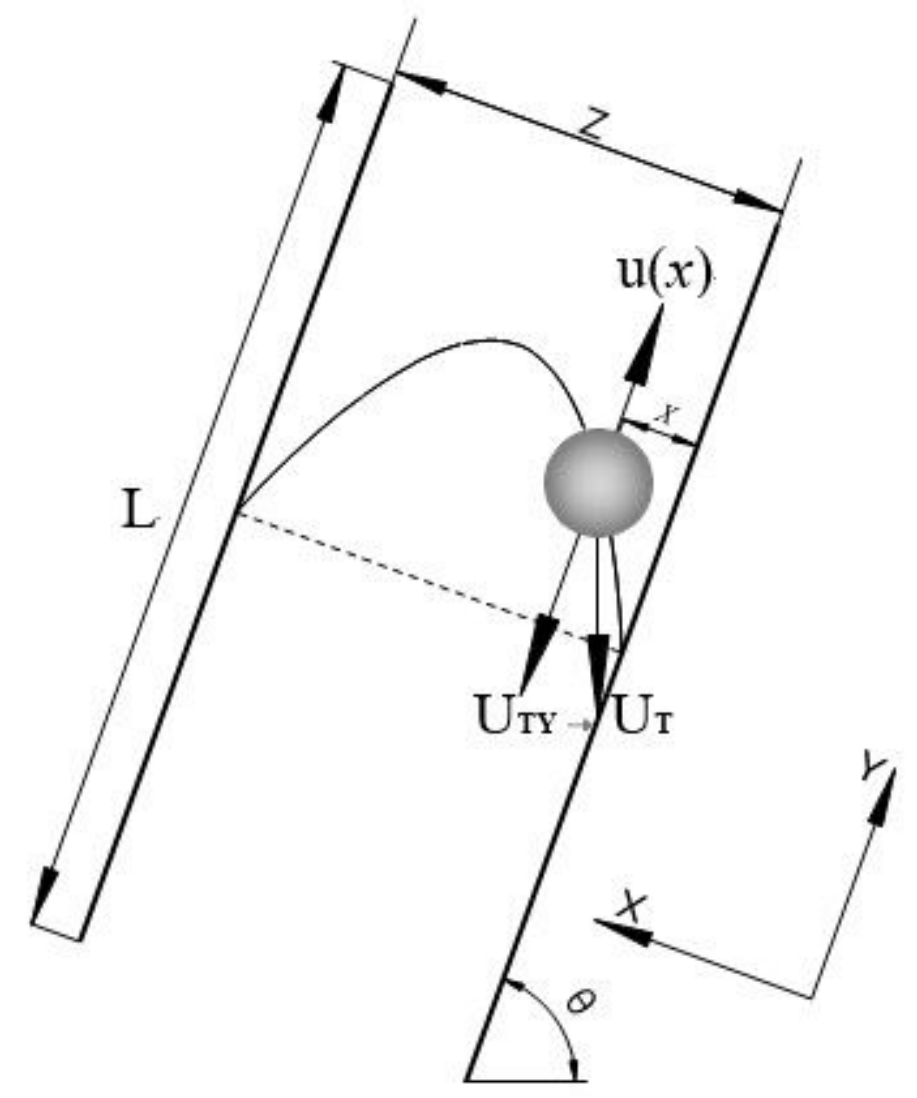

Figure 2

Figure 2 - Analysis the force for the particle in inclined channels [18]
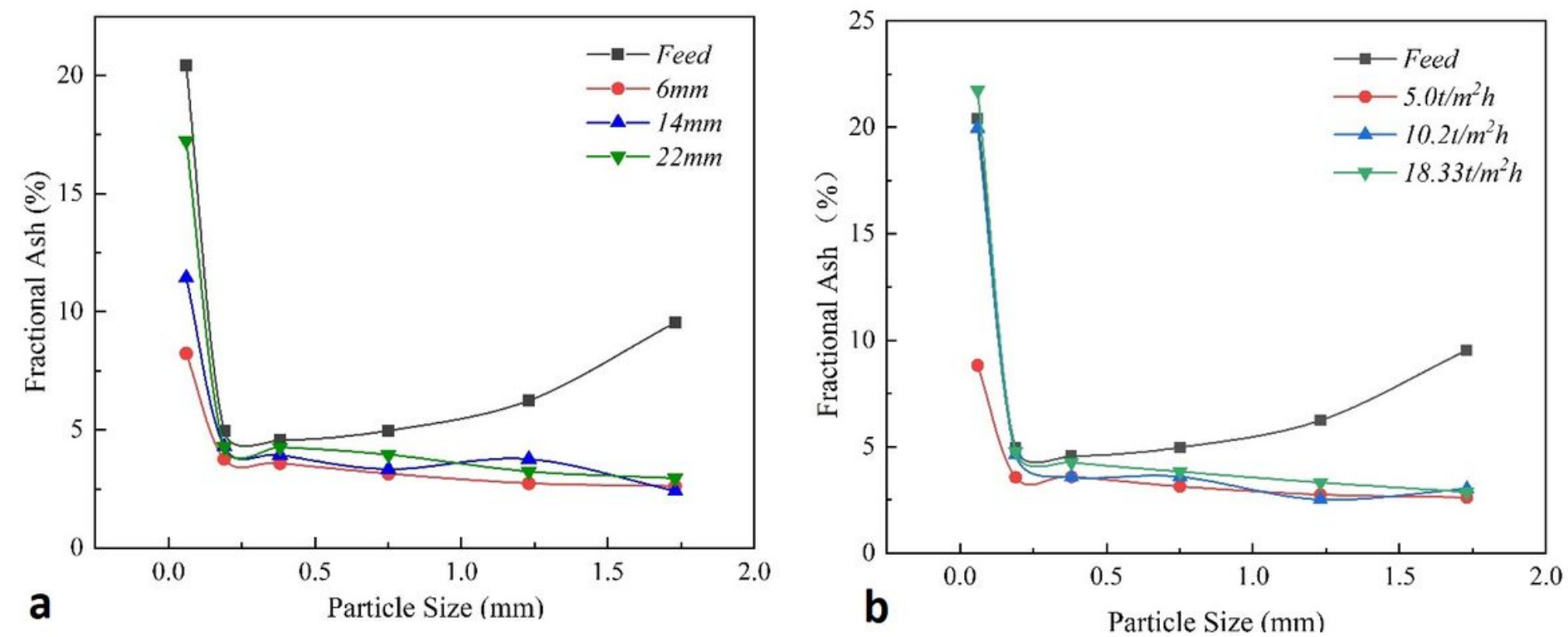

Figure 3 
Figure 5 - a Ash content of overflow products with different spacing b Ash content of underflow products with different spacing The influence of spaced channel on the separation performance of the Reflux Classifier. Fractional ash \% curve of the closed narrow size fractions of the feed, overflow, and underflow were obtained according to different channels widths including of $6 \mathrm{~mm}, 14 \mathrm{~mm}$ and $22 \mathrm{~mm}$. (Experiments $1,2,3)$
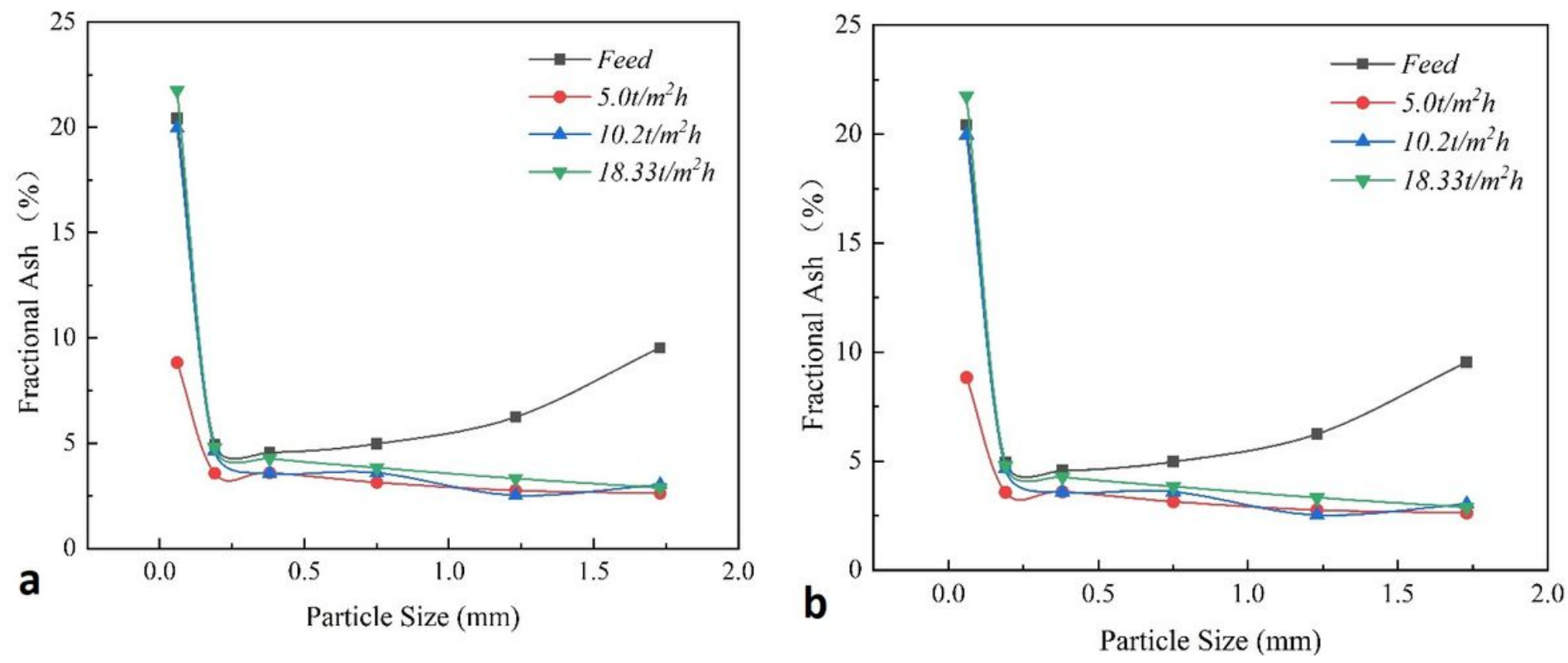

Figure 4

Figure 6 - a Ash content of overflow products with solid throughput b Ash content of underflow products with different solid throughput The influence of solid throughput on the separation performance of the Reflux Classifier. Fractional ash \% curve of the closed narrow size fractions of the feed, overflow, and underflow were obtained according to different values of the solid throughput including of 5.0 $\mathrm{t} / \mathrm{m} 2 \mathrm{~h}, 10.20 \mathrm{t} / \mathrm{m} 2 \mathrm{~h}, 18.33 \mathrm{t} / \mathrm{m} 2 \mathrm{~h}$. (Experiments 1, 4, 5)
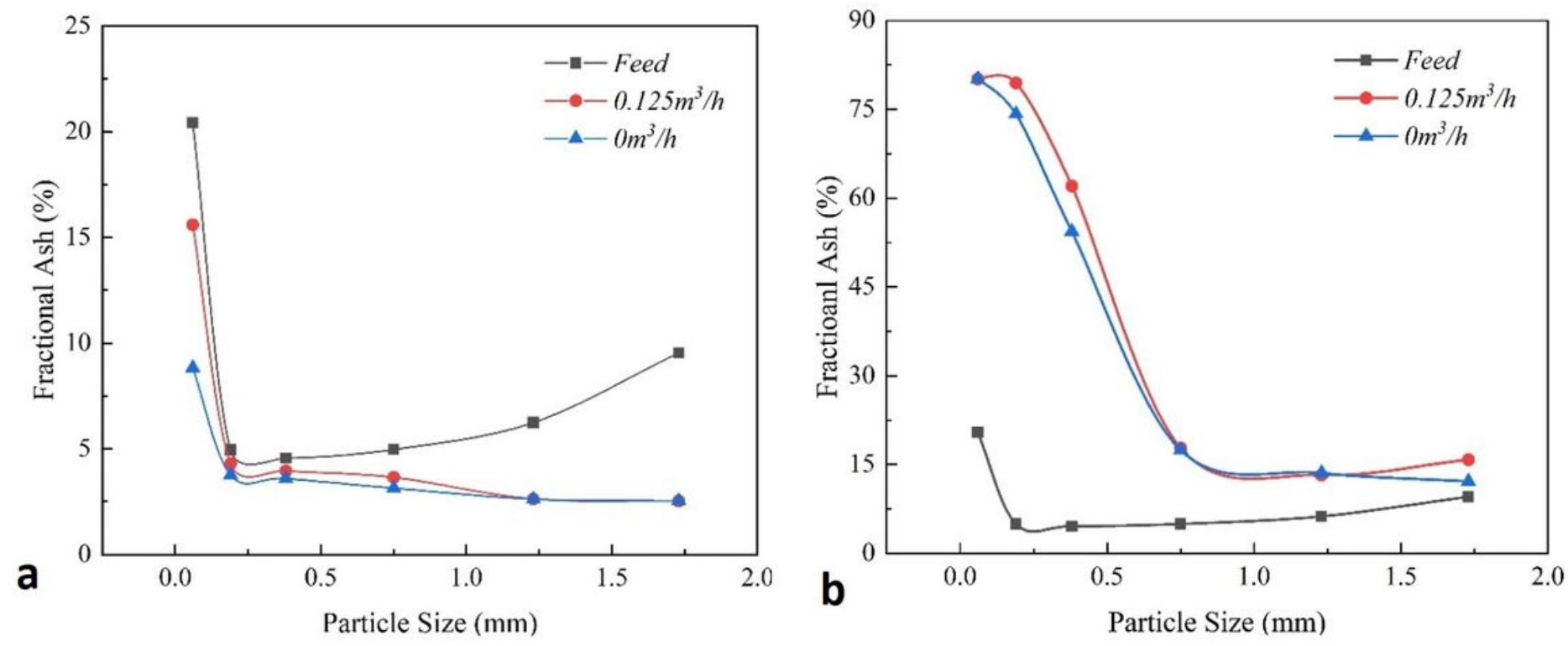

Figure 5 
Figure 7 - a Ash content of overflow products with split fluidization b Ash content of underflow products with different split fluidization The influence of split fluidization on the separation performance of the Reflux Classifier. Fractional ash \% curve of the closed narrow size fractions of the feed, overflow, and underflow were obtained according to different values of the split fluidization including of $0.125 \mathrm{t} 3 / \mathrm{h}$ and $0 \mathrm{t} 3 / \mathrm{h}$. (Experiments 1, 6)

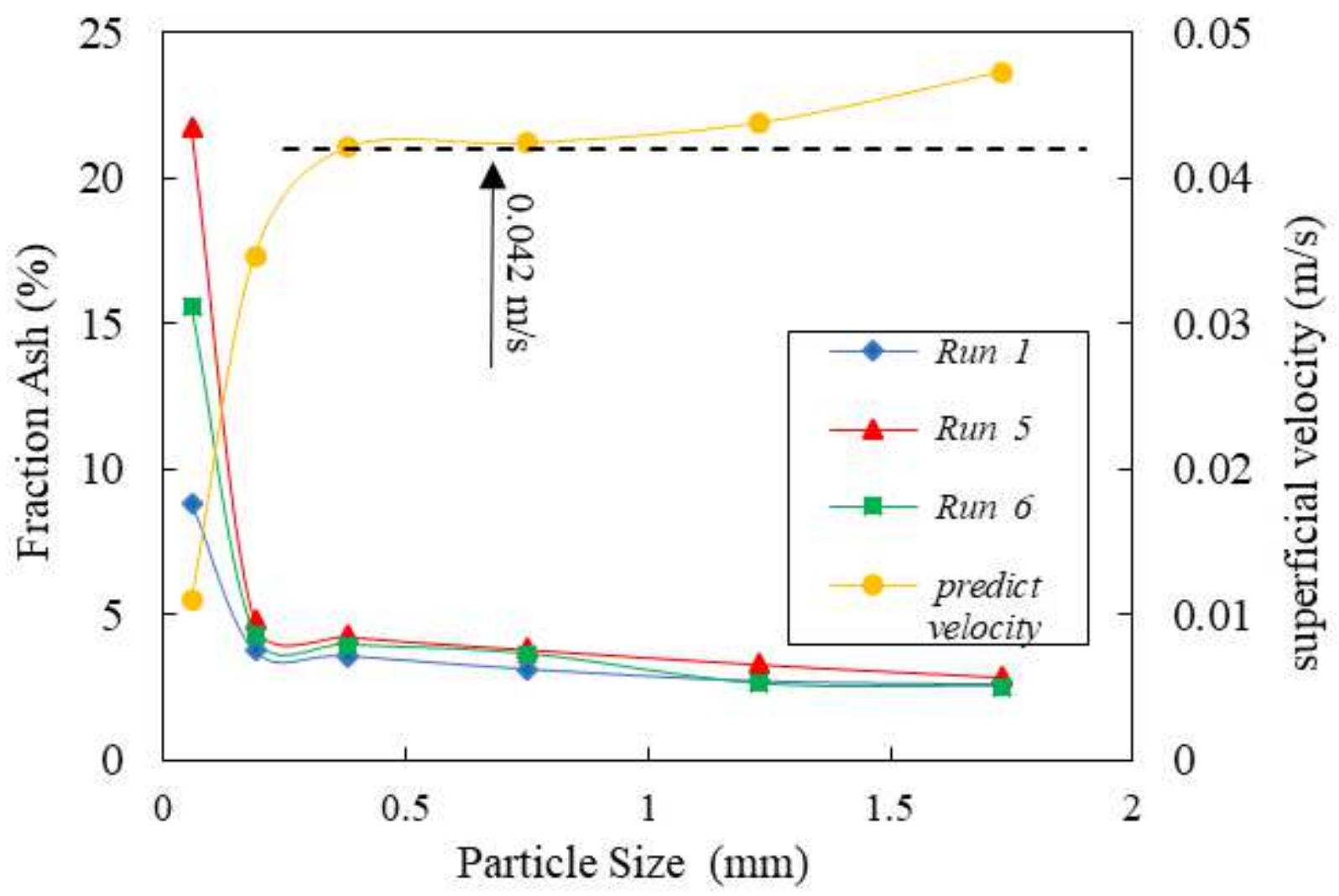

Figure 6

Figure 8 - Relate between particle size and ash content of overflow product in continuous separation. 


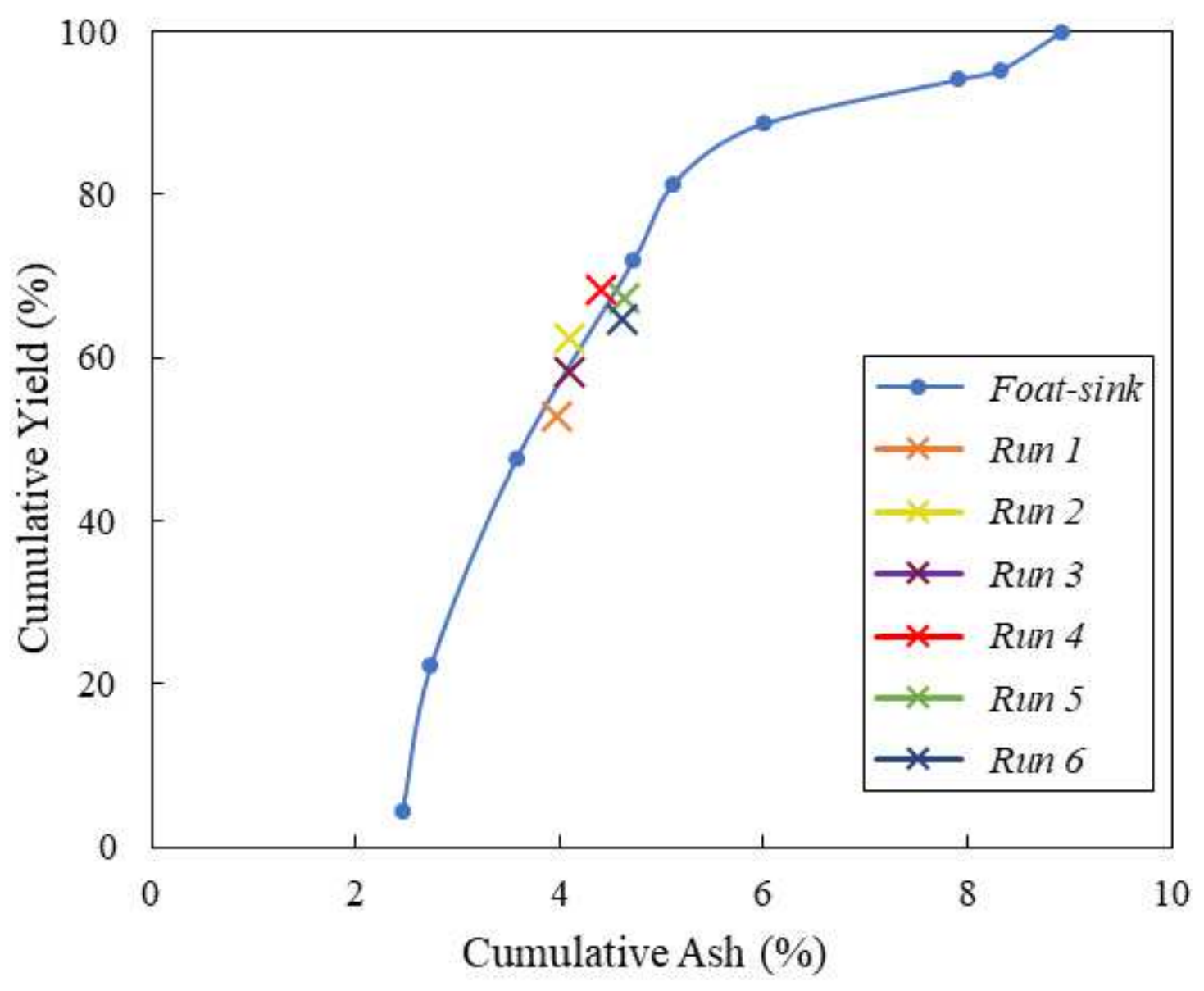

Figure 7

Figure 9 - The washability curve denotes the highest possible yield \% for the given product ash \%. Ashyield Relation of 6 Run of overflow products in continuous separation test. 